\title{
Overview of Flood Barrier Testing Strategies Project
}

Zhegang Ma, Sai Zhang, Curtis L Smith March 2020

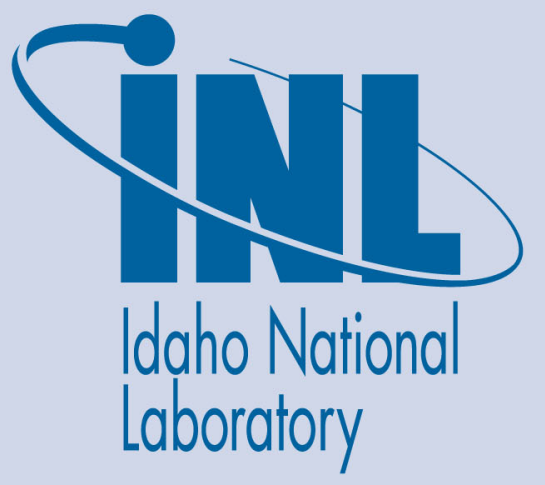

The INL is a U.S. Department of Energy National Laboratory operated by Battelle Energy Alliance 


\title{
Overview of Flood Barrier Testing Strategies Project
}

\author{
Zhegang Ma, Sai Zhang, Curtis L Smith
}

March 2020

Idaho National Laboratory Idaho Falls, Idaho 83415

http://www.inl.gov

Prepared for the U.S. Department of Energy Office of Nuclear Energy Under DOE Idaho Operations Office

Contract DE-AC07-05ID14517 


\section{Overview of Flood Barrier Testing Strategies Project}

Zhegang Ma, Ph.D., P.E.

Sai Zhang, Ph.D.

Curtis Smith, Ph.D.

NRC Flood Barrier Testing Strategies Workshop

March 12, 2020

Rockville, MD, USA 


\section{Background}

$>$ Flood barriers are part of the nuclear power plant (NPP) flood protection features that prevent structures, systems, and components (SSCs) from experiencing flooding and mitigate the effects of flooding

$>$ Flood barriers can be on-site or off-site, permanent or temporary, active or passive

$>$ Permanent: external and internal walls, watertight doors, and flood penetration seals

$>$ Temporary: sandbags, temporary walls, removable doors, and stop-logs
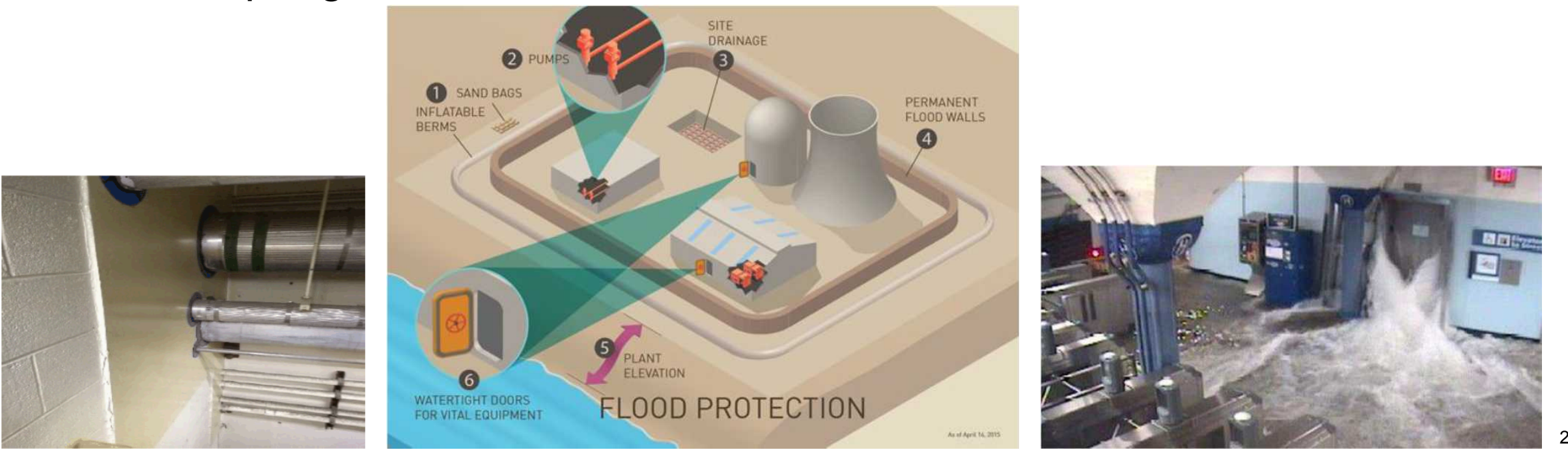


\section{Background (cont'd)}

$>$ Operational experiences have shown that flood barrier performance could have significant safety implications, especially as the domestic reactor fleet ages

$>$ Inadequate design or installation

$>$ Non-functional due to aging and degradation

$>$ Inadequate inspection procedures or acceptance criteria for detecting deficient flood barriers

$>$ Deficient analyses associated with flood barriers

$>$ Discrepancies between tested flood barrier designs and plantinstalled designs

$>$ Installed barriers modified but not evaluated or tested

$>$ Deficient flood barriers due to lack of fill or being composed of non-watertight materials

$>$ Missing penetration seals or internal conduit seals 


\section{Background (cont'd)}

$>$ Flood barriers must be adequately tested, inspected, and maintained to provide reasonable assurance that they can perform their intended functions in the event of flooding

$>$ Project objective: to identify and assess options and develop strategies for testing NPP flood barriers

$>$ Investigate the current state of NPP decommissioning which impacts opportunities and challenges for harvesting

$>$ Consider technical and logistical challenges in harvesting and laboratory testing of flood barriers

$>$ Potential alternatives to harvesting, such as in-situ testing, enhanced inspection 


\section{Project Team}

$>\mathrm{INL}$

$>$ Curtis Smith, PI

$>$ Zhegang $\mathrm{Ma}$

$>$ Sai Zhang

$>$ John Biersdorf

$>$ Idaho State University

$>$ Chad Pope, Professor 


\section{Project Status}

$>$ Task 1: Review Available Information on Flood Barriers

$>$ Licensee walkdown reports

$>$ Previous NRC research

$>$ Nuclear Energy Institute (NEI), Electric Power Research Institutes (EPRI) reports

$>$ Information from vendors

$>$ Decommissioning info

$>$ Other government agencies (e.g., U.S. Army Corps of Engineers)

$>$ International organizations (e.g., Nuclear Energy Agency)

$>$ Status - Task report drafted, reviewed, and revised 


\section{Project Status (cont'd)}

$>$ Task 2: Flood Barrier Testing Workshop

$>$ Present preliminary results from the project

$>$ Engage industry stakeholders and technical experts to provide inputs and insights

$>$ Status - Ongoing

$>$ Task 3: International Harvesting Workshop

$>$ Cancelled

$>$ Task 4: Knowledge Transfer

$>$ Participate the NRC PFHA Research Workshop - Completed

$>$ Prepare a draft NUREG/CR report - 9/15/2020 


\section{Project Preliminary Results}

$>$ Literature Review (presented separately)

$>$ Including plant flooding walkdown report review

$>$ Flood Barrier Categorization and Terminology

$>$ Flood Barrier Overview

$>$ Potential Flood Barrier Testing Facilities

$>$ Previous Flood Barrier Tests (presented separately)

$>$ Flood Barrier Testing Strategies

$>$ Considerations in developing flood barrier testing strategies 


\section{Flood Barrier Overview}

$>$ Categorization

$>$ On-site vs. Off-site

$>$ Permanent vs. Temporary

$>$ Active vs. Passive

$>$ On-site Permanent

$>$ Penetration Seals

$>$ Watertight Doors

$>$ On-site Temporary
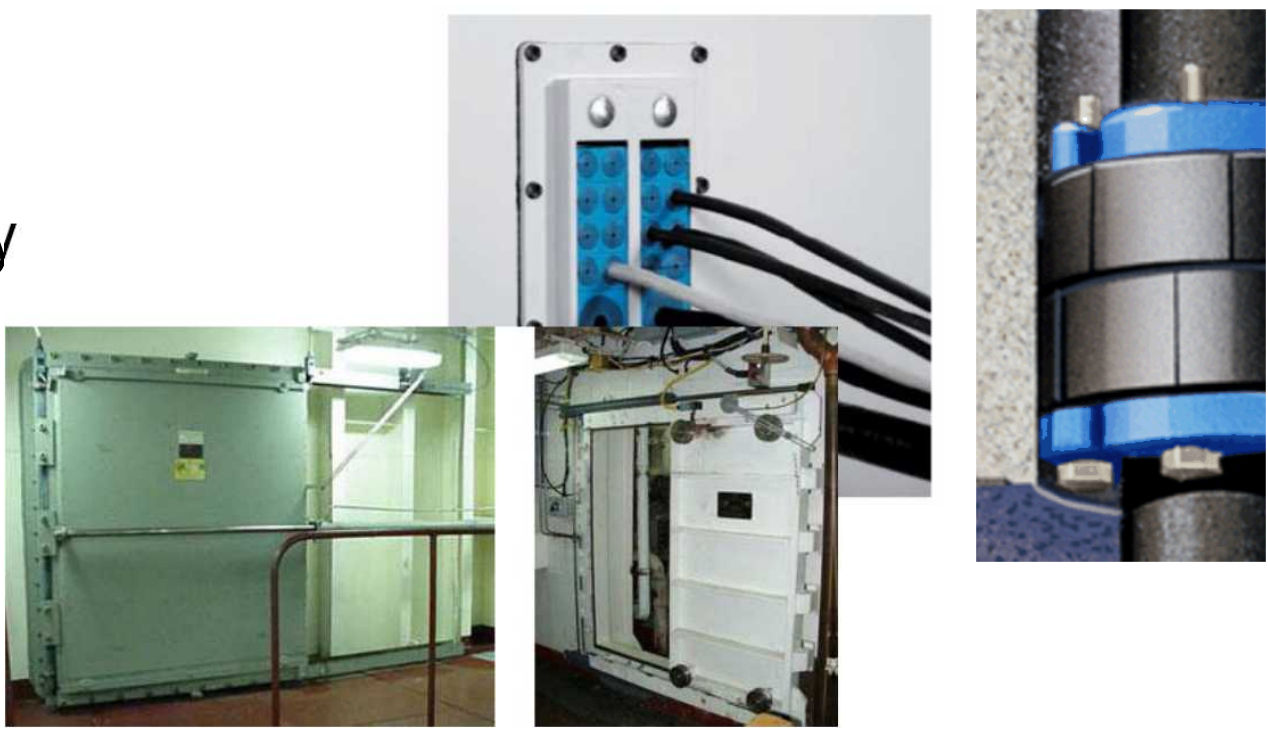

$>$ Disposable - absorbent pad, etc.

$>$ Reusable - floodgates, hydrostatic tarp, etc.
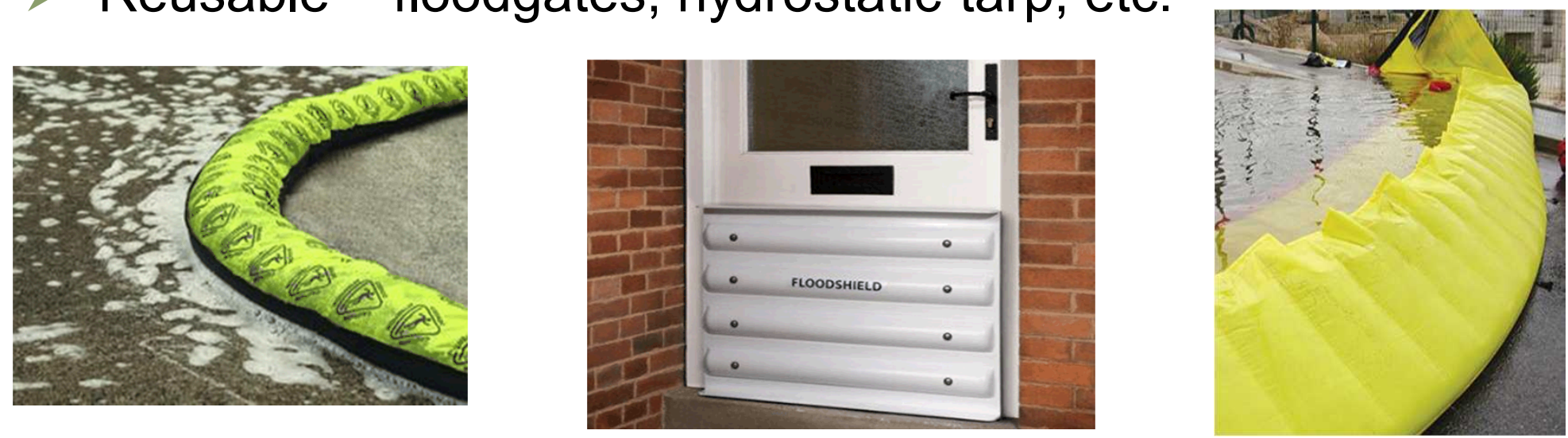


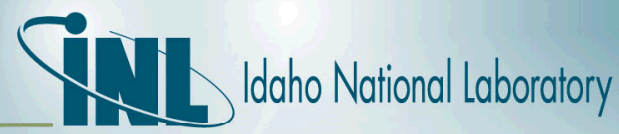

\section{Potential Flood Barrier Testing Facilities}

\section{$>$ Operating Plants}

$>$ Nearly 100 licensed NPPs in the United States

$>$ Potential testing facilities for in-situ non-destructive testing or enhanced inspection

$>$ Testing must be carefully incorporated into plant's O\&M schedule to avoid inadvertently impacting the safety and reliability of plant operations

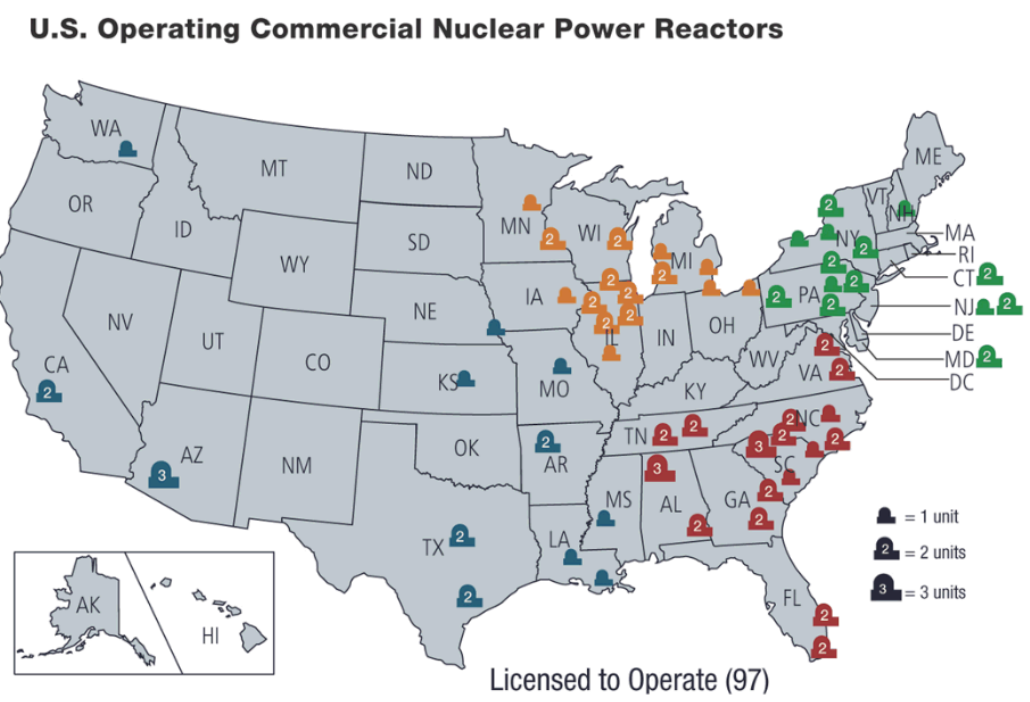

QU.S.NRC 


\section{Potential Flood Barrier Testing Facilities}

$>$ Decommissioning Plants

$>$ About 20 power reactors undergoing decommissioning

$>$ Major Decommissioning Companies

$>$ Holtec Decommissioning International (HDI)

$>$ Oyster Creek, Pilgrim

$>$ Purchase agreements for Palisades and Indian Point

$>$ Northstar

$>$ Vermont Yankee

$>$ EnergySolutions

$>$ Zion and La Crosse 


\section{Potential Flood Barrier Testing Facilities}

$>$ Other Testing Facilities - Idaho State University Flood Testing Facility

$>$ Portal Evaluation Tank (PET)

$>$ A steel, semi-cylindrical tank with a height and diameter of $8 \mathrm{ft}$, can hold up to 2,000-gal of water

$>5$ HP submersible pump inside a 8,000-gal water reservoir

$>$ Inlet electromagnetic flow meter, ultrasonic depth sensor, and pressure transducer, pressure and air relief valves and a digital pressure gauge
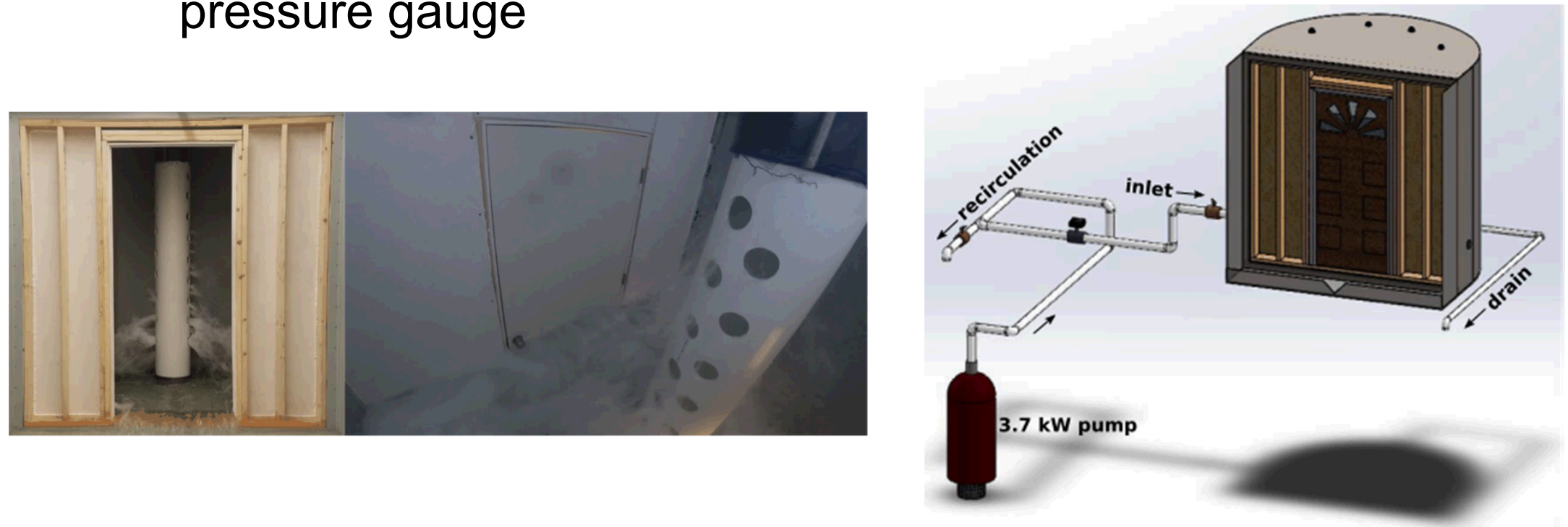


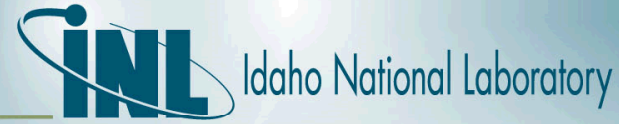

\section{Potential Flood Barrier Testing Facilities}

$>$ Other Testing Facilities - Framatome Laboratory Flood Testing Facility

$>$ Test apparatus for research on penetration seal testing protocol

$>$ Three main components

$>$ Pressure chamber

$>$ Concrete test deck

$>$ Water leakage measurement system
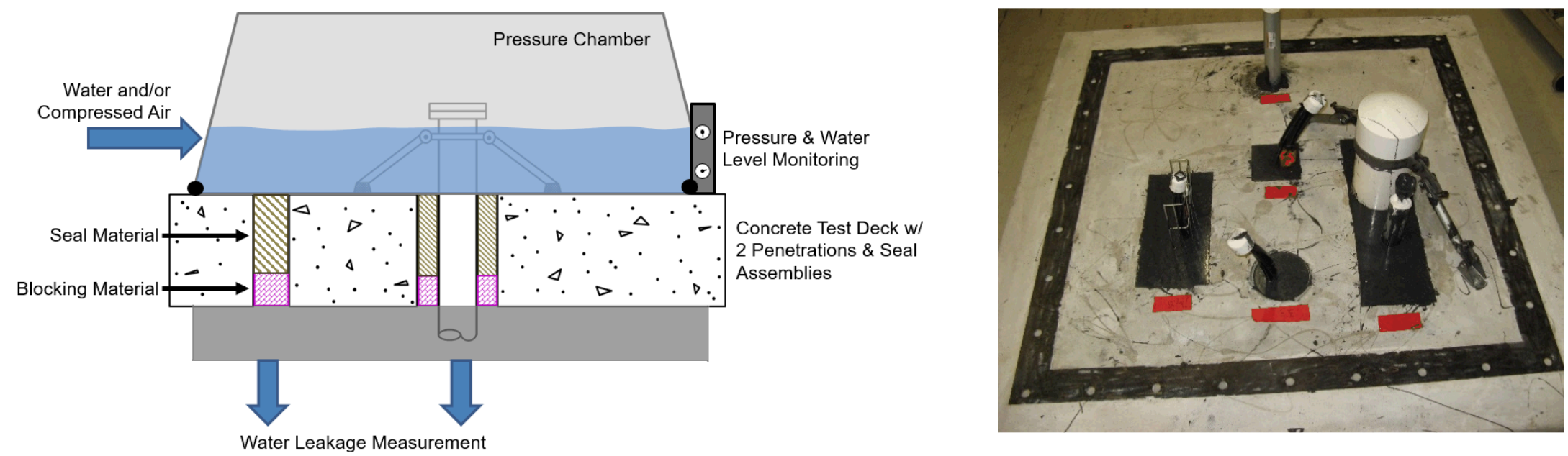


\section{Flood Barrier Testing Strategies Considerations}

$>$ What to be tested?

$>$ Hundreds of flood barriers

$>$ Risk/Safety ranking

$>$ Location (i.e., Accessibility)

$>$ Type of Flood Barriers for Testing

$>$ Seals, Doors, Walls, Floors, Temporary Barriers

$>$ Codes and Standards

$>$ Penetration Seals

$>$ UL 1479 and UL 2079 for pressure testing of fire barriers

$>$ Doors

$>$ Door testing standards, e.g., ASTM E331

$>$ Analytical methods

$>$ Base Structures 


\section{Flood Barrier Testing Strategies (Cont'd)}

$>$ Protocols and Plans

$>$ Testing Locations

$>$ In-situ (in plant, in place)

$>$ Ex-situ but on-site (not in place, but on-site)

$>$ Ex-situ and off-site (off-site testing facilities)

$>$ Flood Effect and Failure Modes

$>$ Hydrostatic pressure, hydrodynamic pressure, debris impact

$>$ Excessive leakage, loss of integrity, displacement, overtopping

$>$ Mediums

$>$ Water, air, steam

$>$ Standing (without pressure) - static pressure testing

$>$ Under pressure (via pump or air) - dynamic pressure testing 


\section{Flood Barrier Testing Strategies (Cont'd)}

$>$ Protocols and Plans

$>$ Parameters

$>$ Input Parameters: test pressure, water levels, flow rate, duration of applied pressure, rate of pressure change, debris size

$>$ Output Parameters: leakage rate, maximum pressure before loss of integrity

$>$ Other Parameters: water temperature, test duration, time history

$>$ Acceptance Criteria

$>$ In accordance with the functional requirements

$>$ No/neglect leakage, maintained integrity under static and/or dynamic pressure

$>$ Other aspects

$>$ Destructive vs non-destructive, sample vs actual flood barriers 


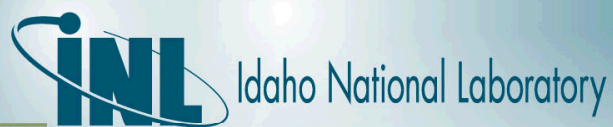

\section{Flood Barrier Testing Strategies (Cont'd)}

$>$ We want to engage industry stakeholders and technical experts for insights and inputs

$>$ During the workshop

$>$ After the workshop

Thomas.Aird@nrc.gov

Curtis.Smith@inl.gov

Zhegang.Ma@inl.gov 